\title{
Determining the construction sequence of the Preah Vihear monument in Cambodia from its sandstone block characteristics
}

\author{
Etsuo Uchida ${ }^{1 *}\left(\mathbb{D}\right.$, Akinori Mizoguchi ${ }^{2}$, Hiroya Sato ${ }^{1}$, Ichita Shimoda ${ }^{3}$ and Ryota Watanabe ${ }^{1}$
}

\begin{abstract}
The Preah Vihear monument in Cambodia, located close to the border with Thailand, was one of the Khmer temples registered on the UNESCO World Heritage List as a Cultural Property in 2008. It consists of masonry buildings constructed of siliceous sandstone blocks. In this study, the construction sequence of its buildings was inferred from the chemical composition, magnetic susceptibility, and size of the sandstone blocks, along with pediment end style, and the presence or absence of reliefs on the tympana of adjacent buildings. Five construction stages were identified. We revealed that the Western Annex Hall (N2) is the oldest edifice in the Preah Vihear monument. We also reconfirmed that the Preah Vihear monument was constructed over a range of years, spanning the Bakheng style period to the Angkor Wat style period (the end of the 9th century to the end of 12th century). It was clarified that during the construction of Preah Vihear, the style of pediment ends changed from pediments ending in scrolls made from one block, to pediments ending in scrolls made from two blocks, and finally to pediments ending in five-headed nagas. Over the same time span, the size of the sandstone blocks used in construction increased markedly.
\end{abstract}

Keywords: Preah Vihear, Sandstone, Chemical composition, Magnetic susceptibility, Portable XRF, Construction sequence, Cambodia

\section{Background}

The Preah Vihear monument in Cambodia is located near to the border with Thailand (it is called Khao Phra Wihan in Thailand), on the southern margin of the Khorat Plateau (Fig. 1) [1-3] and consists of masonry buildings constructed from sandstone blocks. The monument was occupied by Khmer Rouge since 1989 and released in 1998. The maintenance of the monument was conducted by the Cambodian Government during 2000-2002. The monument was designated as a UNESCO World Cultural Heritage Site in 2008 .

The study of the Preah Vihear monument was initiated by Barth [4] and Bergaigne [5] and then followed by Aymonier [6], Lunet de Lajonquiere [7], Groslier [8], Parmentier [9], Cœdès [10], Jacques and Freeman

\footnotetext{
*Correspondence: weuchida@waseda.jp

1 Department of Resources and Environmental Engineering, Waseda

University, Ohkubo 3-4-1, Shinjuku-ku, Tokyo 169-8555, Japan

Full list of author information is available at the end of the article
}

[11], and Sahai [12]. These studies were conducted from architectural and art-historical viewpoints or based on inscriptions. The Preah Vihear monument is believed to have been constructed by the Khmer people between the 9th and 12th century AD. Groslier [8] and Parmentier [9] considered that the Preah Vihear monument consisted originally of wooden buildings and they were later replaced by masonry buildings.

Parmentier [9] and Sahai [12] created construction chronology of the Preah Vihear monument based on architectural evidences and inscriptions, respectively. The construction chronology inferred by them is based on unclear architectural traces and limited inscriptions, leaving room to be reconsidered. In contrast to the previous studies, this study infers objectively the construction sequence of the monument based on its building stone characteristics such as the chemical composition, magnetic susceptibility, and size of the sandstone blocks, taking into account architectural, iconographic and epigraphic evidences. 


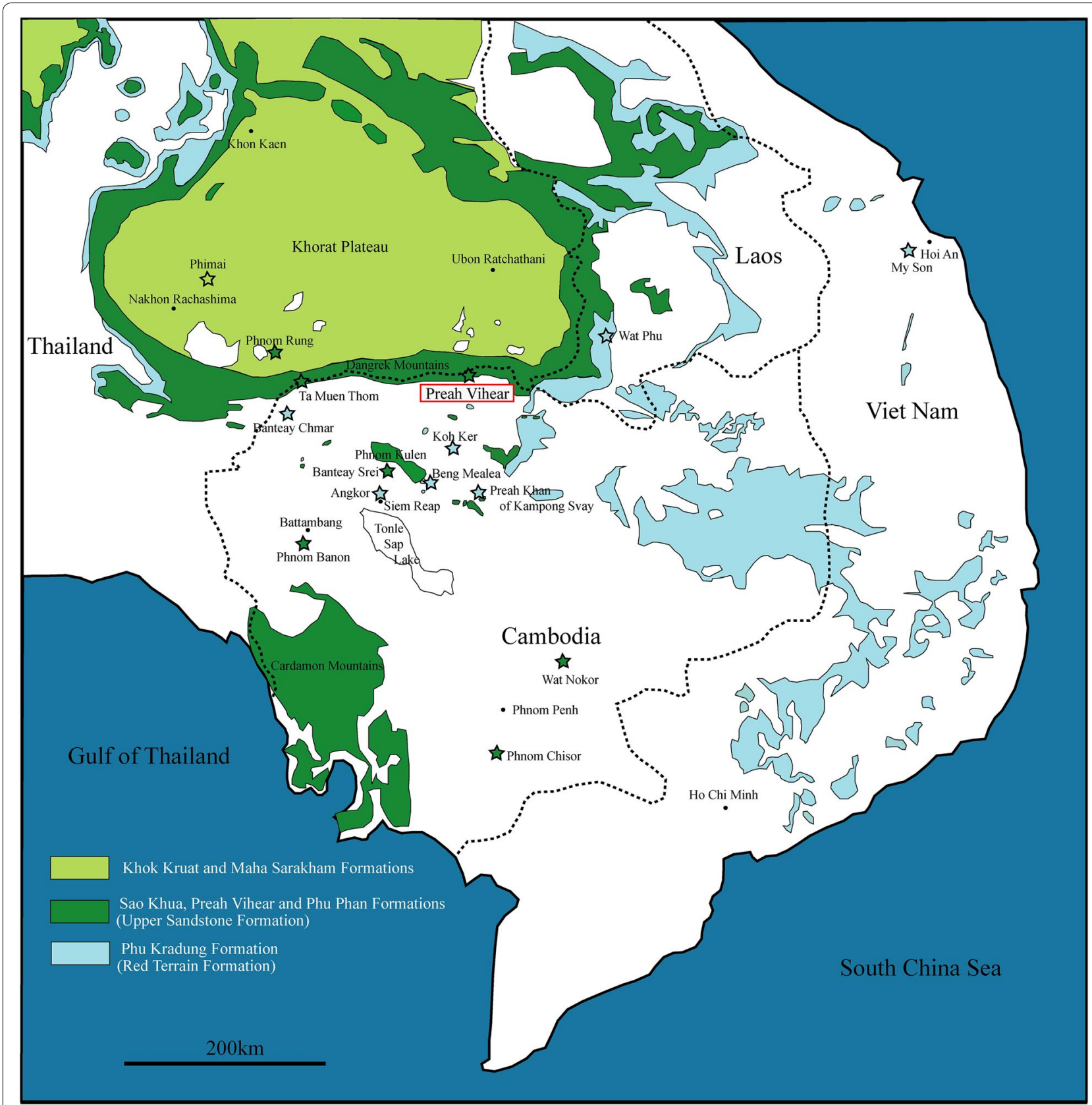

Fig. 1 Location of the representative Khmer monuments, including the Preah Vihear monument [1]. The provenance of sandstones used for constructing the Khmer monuments is also shown in this figure [2,3]. The colored asterisks for each monument are correlated with the various sandstone formations used to construct them

\section{Buildings in the Preah Vihear monument}

The Preah Vihear temple faces north and is located on a slope of the Dangrek Range that increases in altitude from the north entrance $(550 \mathrm{~m}$ above sea level) to the southernmost end (630 $\mathrm{m}$ above sea level), with a relative height of $500 \mathrm{~m}$ above the plain of Cambodia. The Preah Vihear temple is a horizontally-oriented layout temple on terraced slope as well as the Wat Phu temple in Laos. The distance between the north entrance and the south end is approximately $800 \mathrm{~m}$.

The buildings of the Preah Vihear monument are arranged in four groupings (Fig. 2). The names and symbols used to identify its constituent buildings are from Roveda [13]. The southernmost group is the largest, and 


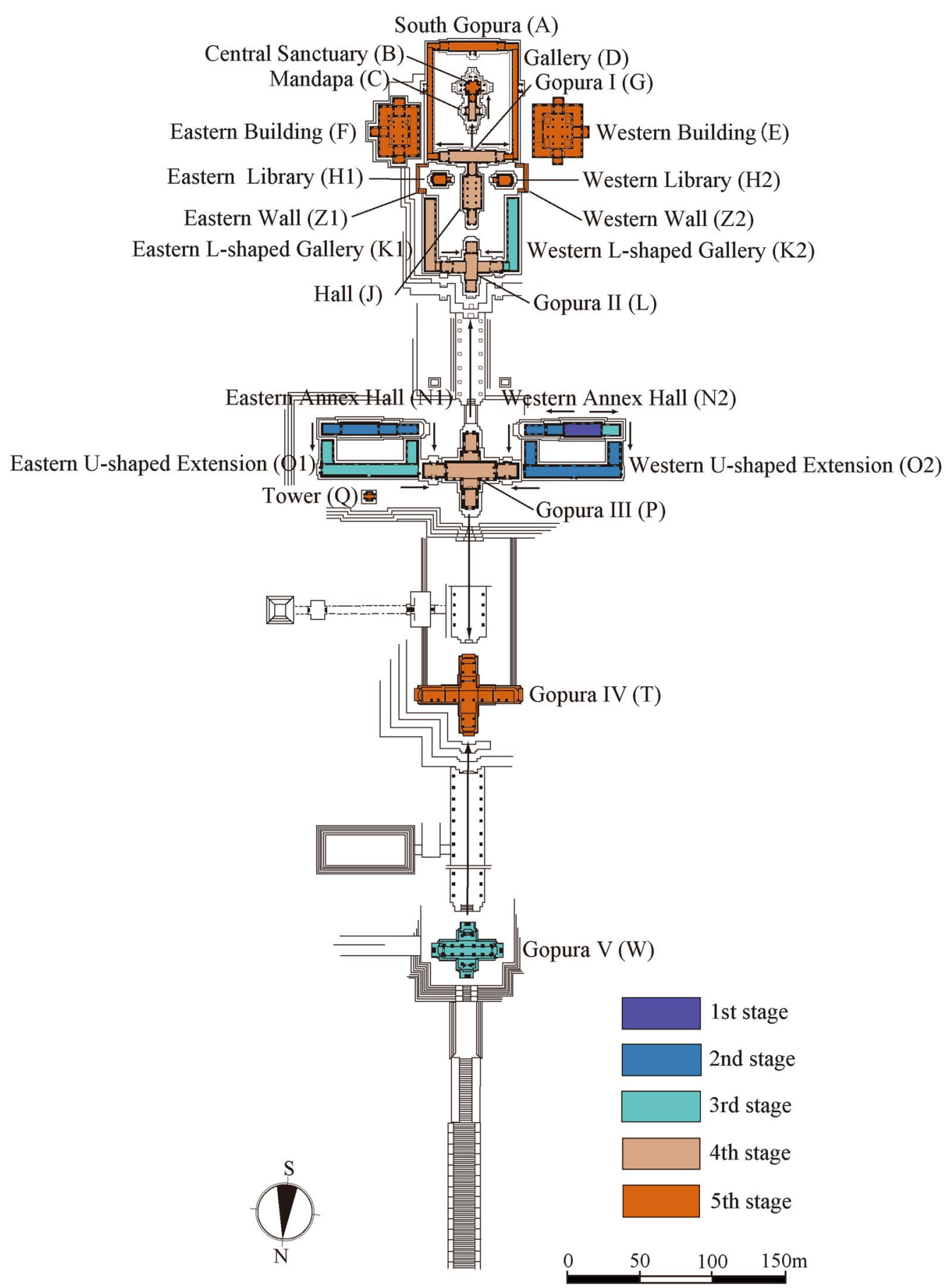

Fig. 2 Plan view of the Preah Vihear monument [13], showing the name and symbol of each building. The five construction stages established in this study based on sandstone characteristics and pediment end style are shown as different colors, grading from blue to red, corresponding to oldest to newest edifices. Arrows indicate the construction sequence with respect to adjacent buildings

consists of the South Gopura (A) (Fig. 3a), Central Sanctuary (B), Mandapa (C), Gallery (D) (Fig. 3a), Western Building (E), Eastern Building (F), Gopura I (G), Libraries (H1 and H2) (Fig. 3b), Hall (J), L-shaped Galleries
(K1 and K2), and Gopura II (L). Relatively large sandstone blocks were used in the South Gopura (A), Central Sanctuary (B), Eastern Building (F), part of the Gallery (D), and part of the Western Building (E). In addition, 

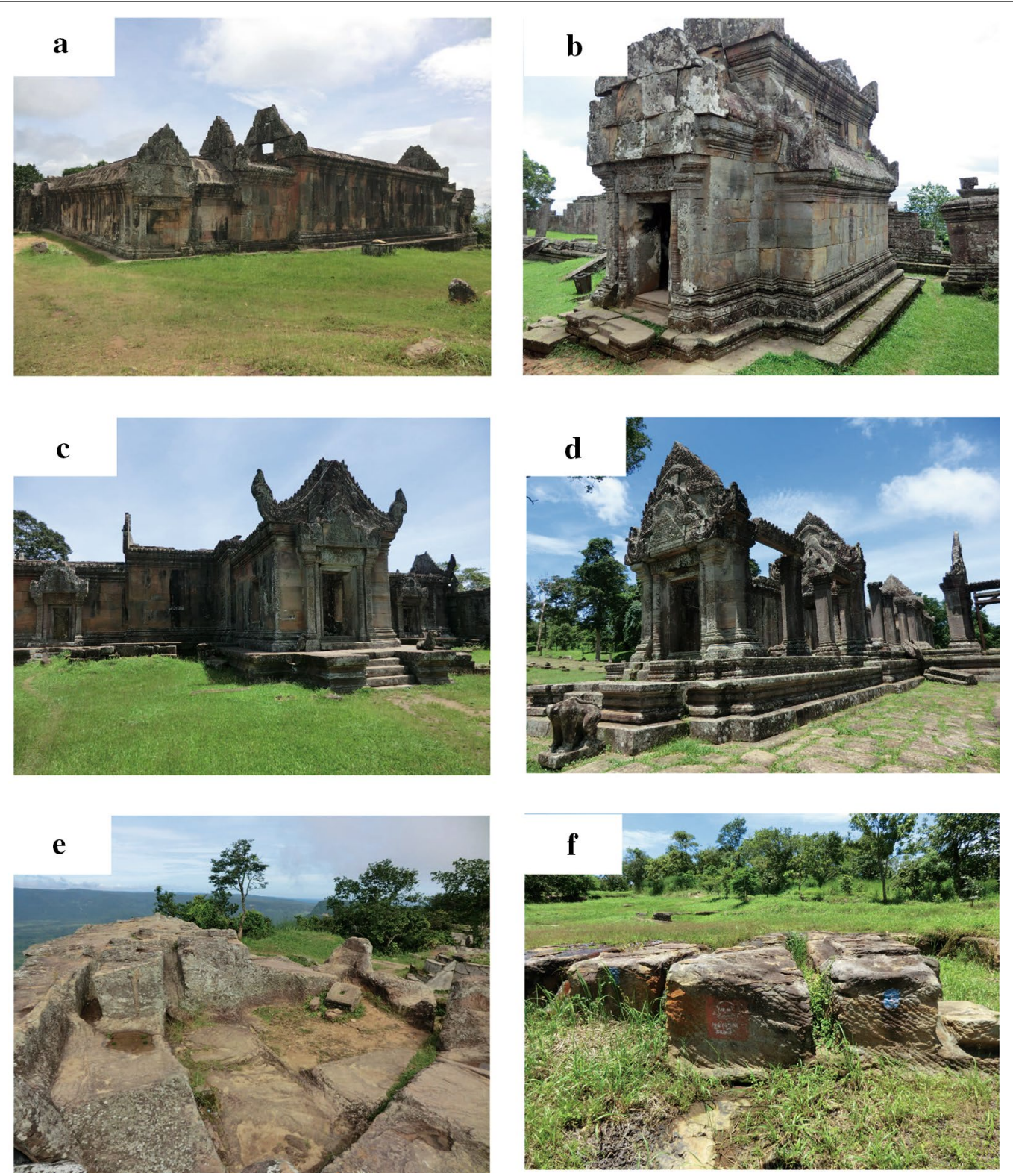

Fig. 3 Photographs of (a) South Gopura (A) and Gallery (D), (b) Eastern Library (H1), (c) Gopura III (P), (d) Gopura IV (T), (e) ancient sandstone quarry for large sandstone blocks situated in the south of South Gopura (A), and (f) ancient sandstone quarry situated in the west of the causeway between Gopura IV (T) and Gopura V (W). Sandstone blocks used for these building have a yellowish-brown color

bedrock was used for part of the Gallery (D) and Western Building (E).

The second group from the south is the second largest, and consists of the Annex Halls (N1 and N2) and U-shaped Extensions (O1 and O2) and Gopura III (P) (Fig. 3c). Bedrock was used for part of the platform of the Western Annex Hall (N2). A small Tower (Q) is located north of the Eastern U-shaped Extension (O1). The third group consists only of the Gopura IV (T) (Fig. 3d), and the fourth group only of the Gopura V (W). The upper structure of the Gopura V (W) has almost collapsed.

\section{Methods}

Magnetic susceptibility of the sandstone blocks was measured using a portable magnetic susceptibility meter (ZH instruments SM30, Brno, Czech Republic), with a reading surface of $5 \times 5 \mathrm{~cm}$. Measurements were made on 50 flat surfaces in each section of each building of the 
monument, and used to calculate average values. Care was taken to avoid blocks covered with algae or lichen $[14,15]$.

Chemical analyses of the sandstone blocks were carried out using a portable X-ray fluorescence analyzer (pXRF; Innov-X Systems Delta Premium, Waltham, MA, USA), measuring in soil mode. The instrument was calibrated using 10 reference rocks from the Geological Society of Japan (JA-1, JA-2, JB-1b, JB-2, JB-3, JG-1a, JG-2, JGb1 , JR-1, and JR-2) [16]. Measurement time was $1 \mathrm{~min}$. Measurements for five sandstone blocks in each building were obtained from flat surfaces, not covered by algae or lichen. These values were averaged.

The size of the sandstone blocks was determined along wall surfaces, showing width and thickness. Dimensions were measured for 25-50 sandstone blocks in each section of each building of the monument, and averaged. In addition, bedding plane orientations in the sandstone blocks were recorded.

Three different types of pediment end styles were recognized in the Preah Vihear monument. We investigated the pediment end style in each building to clarify the relationship with the construction period.

\section{Results}

The results of magnetic susceptibility and pXRF measurements are summarized in Table 1, along with information on block size and pediment end style. Variation in these parameters within the monument is discussed below. The construction sequence (the first to fifth stages) listed in Table 1, but described in more detail later, is inferred from the chemical composition, magnetic susceptibility, sandstone block size, pediment end style, and the presence or absence of relief work on the tympana of the adjacent buildings.

\section{Magnetic susceptibility}

The siliceous sandstone blocks used in the Preah Vihear monument have low magnetic susceptibilities, with average values in the range of $0.011-0.068 \times 10^{-3}$ SI units. In contrast, the gray to yellowish-brown sandstones used in the Angkor monuments, which are feldspathic arenites supplied from the southeastern foot of Mt. Kulen, have higher average magnetic susceptibilities, with values in the range of $0.7-9.1 \times 10^{-3}$ SI units $[14,15,17,18]$.

The sandstone blocks of the central part of the Western Annex Hall (N2) (the first stage) have the lowest magnetic susceptibility in the Preah Vihear monument, averaging $0.011 \times 10^{-3} \mathrm{SI}$ units. The magnetic susceptibility of the sandstone blocks of buildings in the second stage is high, averaging between 0.041 and $0.047 \times 10^{-3}$ SI units. It is low in the third stage, with averages in the range of $0.023-0.045 \times 10^{-3}$ SI units. The Mandapa (C), Gopura
I (G), Hall (J), Gopura II (L), and Gopura III (P) edifices belonging to the fourth stage have the highest values, with averages in the range of $0.049-0.068 \times 10^{-3}$ SI units. The fifth stage buildings have low magnetic susceptibilities, with averages in the range of $0.019-0.042 \times 10^{-3} \mathrm{SI}$ units.

\section{Chemical composition}

The following elements were quantitatively measured using the pXRF: $\mathrm{K}, \mathrm{Ca}, \mathrm{Ti}, \mathrm{Cr}, \mathrm{Mn}, \mathrm{Fe}, \mathrm{Cu}, \mathrm{Zn}, \mathrm{Rb}, \mathrm{Sr}, \mathrm{Y}$, $\mathrm{Zr}$, and $\mathrm{Pb}$. Among these elements, $\mathrm{K}, \mathrm{Ti}, \mathrm{Fe}, \mathrm{Zn}, \mathrm{Rb}$, and $\mathrm{Zr}$ show systematic changes in content in the sandstone blocks used during construction. The contents of $\mathrm{K}, \mathrm{Ti}$, $\mathrm{Fe}, \mathrm{Zn}, \mathrm{Rb}$, and $\mathrm{Zr}$ in the sandstone blocks are relatively low in the first and third stages, but high in the second and fourth stages. They have intermediate values in the fifth stage.

In particular, the contents of $\mathrm{Rb}$ and Ti changed markedly. In the first and third stage edifices, their contents had ranges of $20-30$ and $1050-1100$, and $22-28$ and 800-1000 ppm, respectively. Their contents were higher in the second stage (33-45 and 1240-1510 ppm) and the fourth stage (37-44 and 1330-1480 ppm). The fifth stage had the low to intermediate contents (18-34 and 1000-1360 ppm).

\section{Block size}

In Table 1, block size is listed as: "Small", $<50 \mathrm{~cm}$ in thickness and $<50 \mathrm{~cm}$ in width; "Medium", $<50 \mathrm{~cm}$ in thickness and $50-100 \mathrm{~cm}$ in width; and "Large", $>50 \mathrm{~cm}$ in thickness or $>100 \mathrm{~cm}$ in width. Table 1 shows that block size became larger over the construction time.

The central part of the Western Annex Hall (N2), in contrast to other parts or other buildings, was constructed with the smallest sandstone blocks in the Preah Vihear monument, having an average thickness and width of $35 \times 43 \mathrm{~cm}$. Likewise, the sandstone blocks used in the platform of the Western Annex Hall (N2) are distinctly thin, having a thickness and width of $23 \times 44 \mathrm{~cm}$ on average. In contrast, large sandstone blocks with dimensions of $60-80 \times 130-160 \mathrm{~cm}$ or larger were used in the Central Sanctuary (B), South Gopura (A), Eastern Building (F), Gopura IV (T), part of the Gallery (D), and part of the Western Building (E). Medium-sized sandstone blocks were used in all other buildings.

\section{Bedding plane orientations}

In the upper structure of the central part of the Western Annex Hall (N2), 54\% of sandstone blocks have vertical bedding planes. Many sandstone blocks with square ends are also observed in the platforms of the Eastern Annex Hall (N1) and U-shaped Extensions (O1 and $\mathrm{O} 2$ ), and almost half of them have vertical bedding 


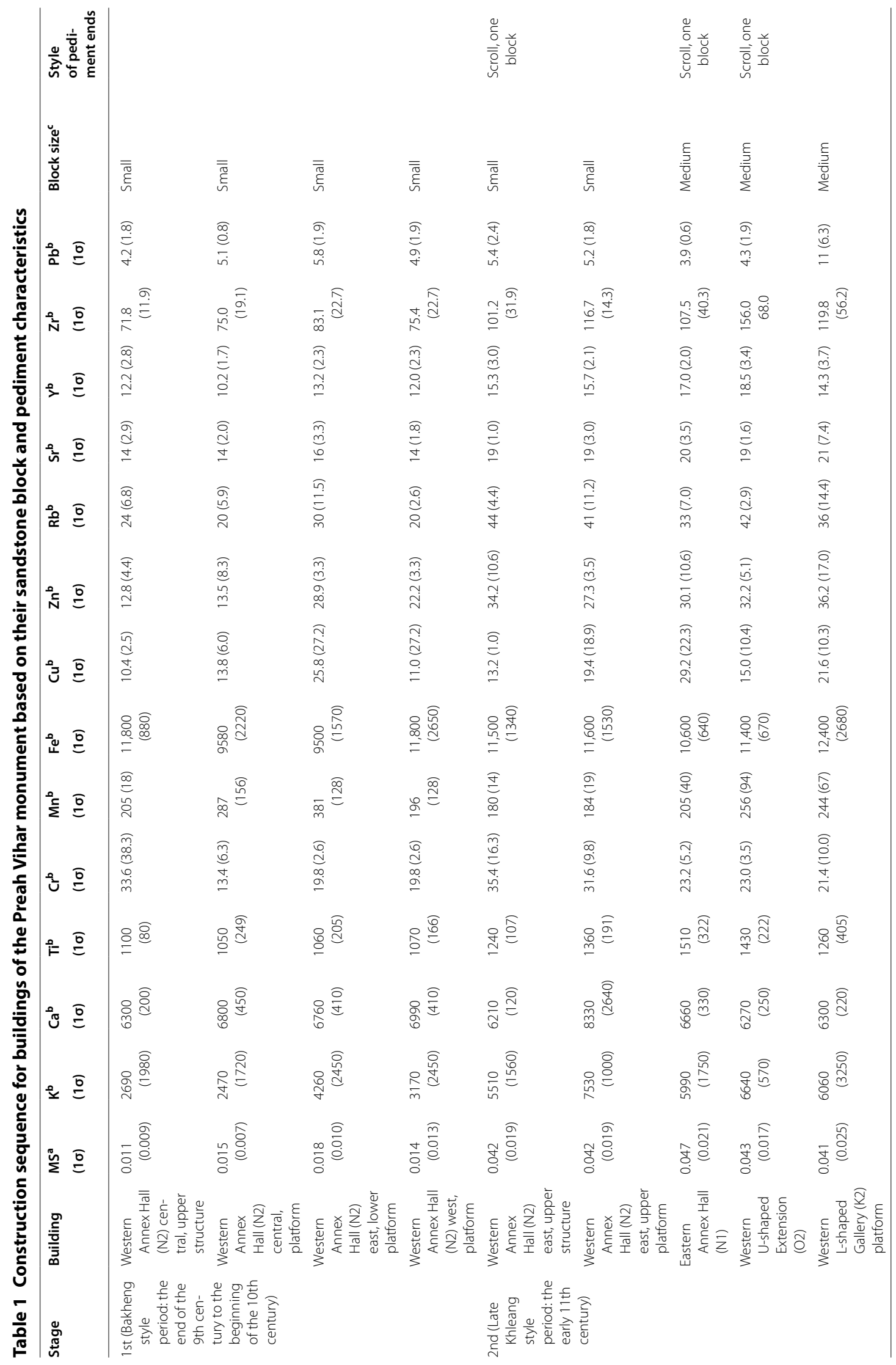




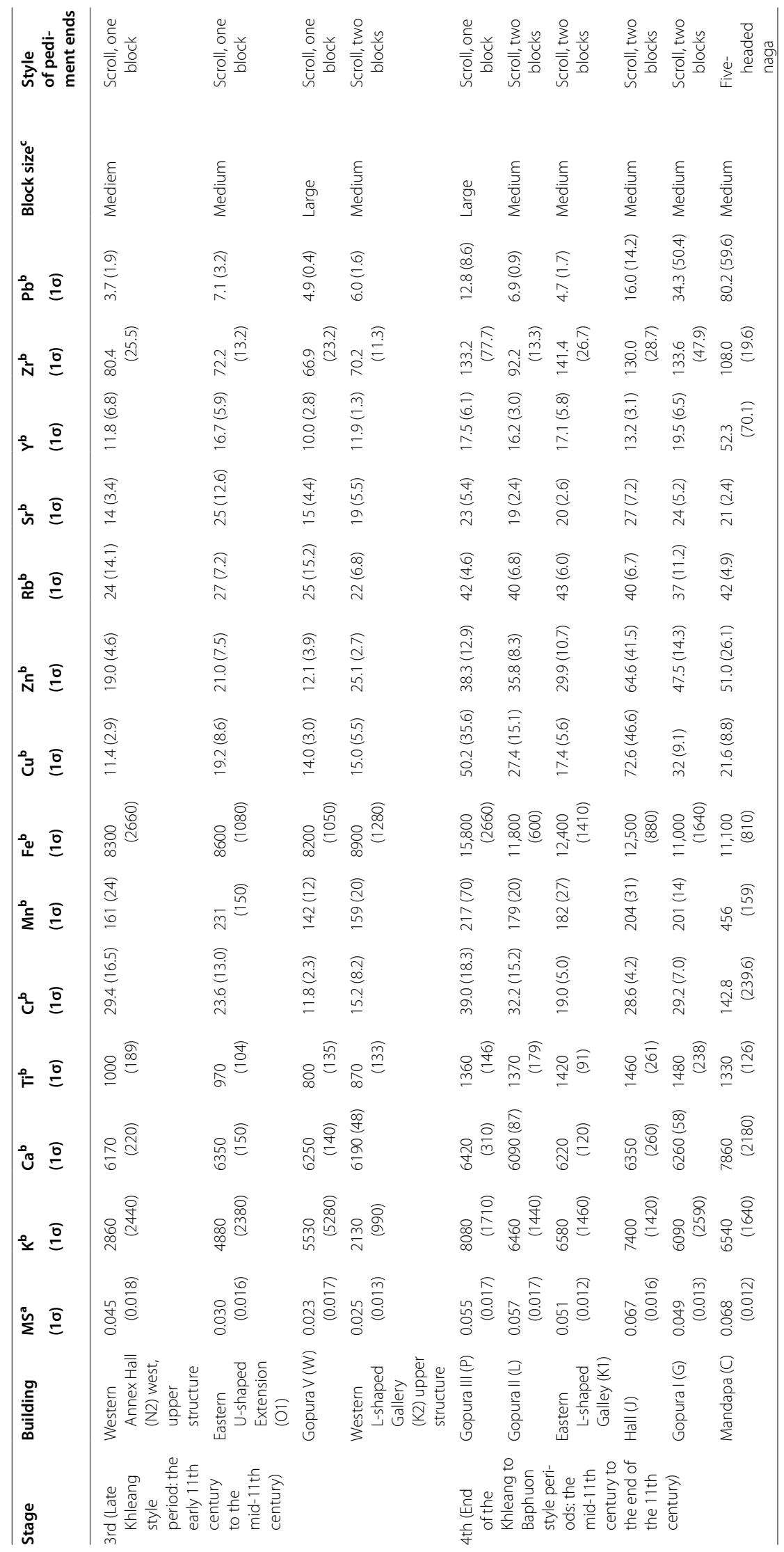




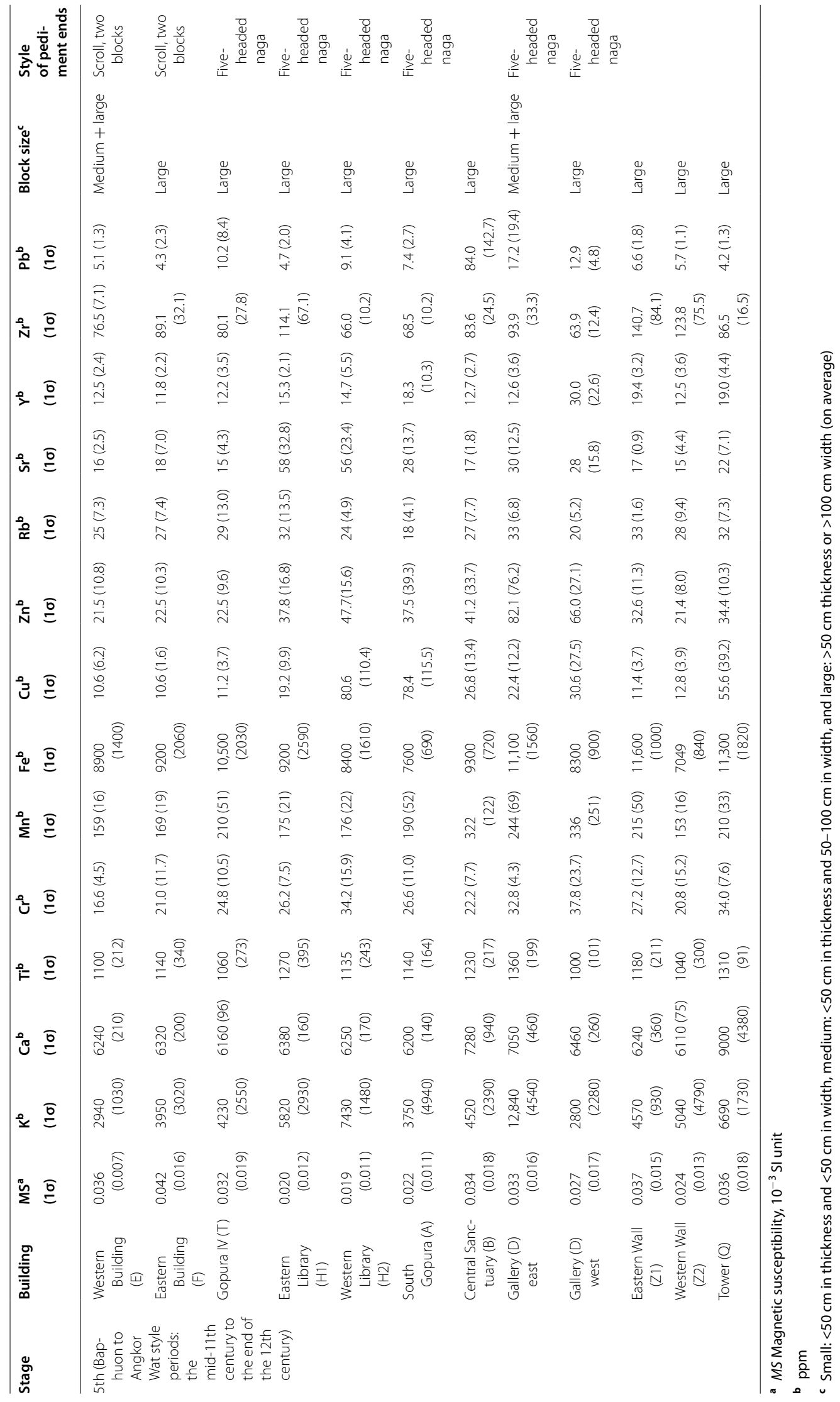


planes. Similarly, sandstone blocks with square ends are frequently observed in the Gopura V (W) and Gopura IV (T), and almost half of them have vertical bedding planes. In contrast, the large sandstone blocks used in the Central Sanctuary (B), South Gopura (A), Gallery (D), and Eastern Building (F) have mainly horizontal bedding planes. Sandstone blocks with face bedding are also observed in the South Gopura (A) and Gallery (D). In the remaining buildings, horizontally-elongated sandstone blocks, with high width/thickness ratios and primarily horizontal bedding planes, were used.

\section{Pediment end styles}

Preah Vihear monument building pediment ends have two styles, based on their terminations (Fig. 4). One style of a pediment ends in scrolls. Such pediments also are
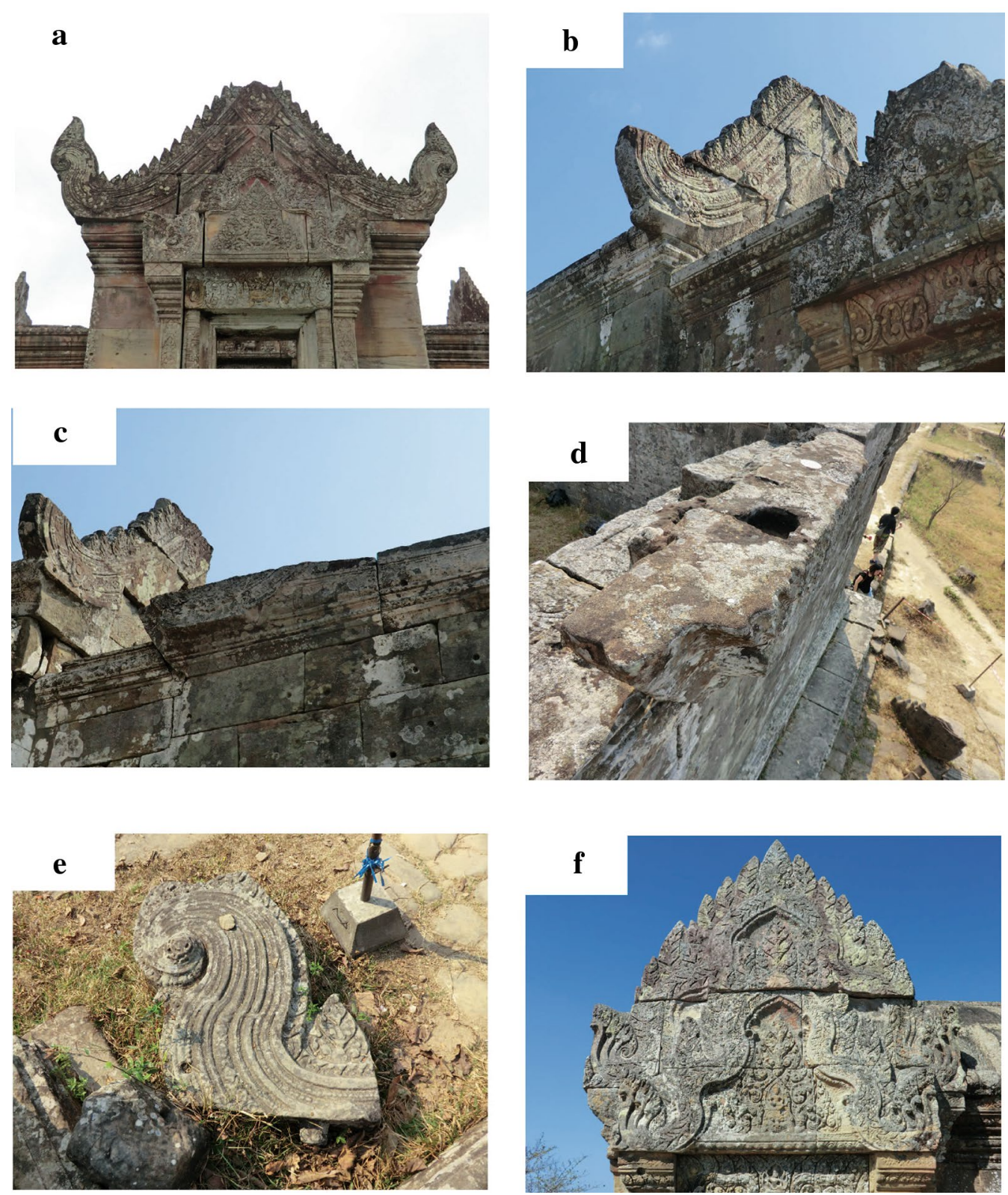

Fig. 4 Images showing pediment end styles at the Preah Vihear monument. a A pediment ending in scrolls made from one block [Gopura III (P)], (b) a pediment ending in scrolls made from two blocks [Gopura II (L)], (c) a pediment ending in scrolls made from two blocks [Western L-shaped Gallery (K2)], (d) a mortise of a pediment ending in scrolls made from two blocks [Western L-shaped Gallery (K2)], (e) a stone block with a tenon that fell from a pediment ending in scrolls made from two blocks [Western L-shaped Gallery (K2)], and (f) a pediment ending in five-headed nagas [Gallery (D)] 
observed in Preah Ko, Koh Ker, and Banteay Srei of the early Angkor period (the end of the 9th century to the mid-10th century). The other style ends in five-headed nagas (Fig. 4f). These pediments are observed in a wide range of periods, from the Banteay Srei style period to the Bayon style period in the middle to late Angkor period (the mid-10th century to the early 13th century). The scroll-style pediment ends can be subdivided into pediments that end in scrolls made from one block (Fig. 4a) and those that end in scrolls made from two blocks (Fig. 4b, c, e), yielding three distinct pediment end styles. The pediments ending in scrolls made from two blocks are likely to be of a later style because they are not found in relatively older monuments such as Preah Ko, Koh Ker and Banteay Srei. The Annex Halls (N1 andN2), U-shaped Extensions (O1 and O2), Gopura III (P), and Gopura V (W) have pediments that end in scrolls made from one block; while the Gopura II (L), Gopura I (G), Hall (J), Galleries II (K1 and K2), Western Building (E), and Eastern Building (F) have pediments that end in scrolls made from two blocks. The South Gopura (A), Mandapa (C), Gallery (D), Libraries (H1 and H2), and Gopura IV (T) have pediments that end in five-headed nagas.

\section{Interpretation and discussion Origin of sandstone}

The sandstone used in the Preah Vihear monument is siliceous sandstone (quartz arenite) and clearly different from the gray to yellowish-brown sandstone (feldspathic arenite) used in the Angkor monuments [17]. This siliceous sandstone of the early Cretaceous age is found within the Khorat Plateau and Mt. Kulen regions (Fig. 1) [19]. In the Angkor monuments, red siliceous sandstone blocks were uniquely used for Banteay Srei. For most of the rest of the Angkor monuments, the Red Terrain Formation (called the Phu Kradung Formation in Thailand) of the late Jurassic to the early Cretaceous supplied the gray to yellowish-brown sandstone. The Red Terrain Formation is overlain conformably by the Upper Sandstone Formation, which consists of siliceous sandstone of the early Cretaceous age [19]. The gray to yellowish-brown sandstone outcrops at the foot of the Khorat Plateau and Mt. Kulen, but was not used in the monuments on the Khorat Plateau. In Thailand, the Upper Sandstone Formation is subdivided into three units, from bottom to top, these are the Preah Vihear (Phra Wihan), Sao Khua, and Phu Phan Formations. These formations are not homogeneous and vary in color. The Preah Vihear Formation is mainly yellowish-brown, with fine to coarse grain size, and magnetic susceptibilities of less than $0.068 \times 10^{-3}$ SI units $\left(0.020 \times 10^{-3}\right.$ SI units on average) [1]. The Sao Khua Formation is primarily red, with fine to medium grain size, and magnetic susceptibilities of $0.016-0.086 \times 10^{-3}$ SI units $\left(0.040 \times 10^{-3}\right.$ SI units on average). The Phu Phan Formation is white, with medium to coarse grain size, and magnetic susceptibilities of less than $0.030 \times 10^{-3}$ SI units $\left(0.008 \times 10^{-3}\right.$ SI units on average). Magnetic susceptibilities are highest for the Sao Khua Formation and lowest for the Phu Phan Formation, with the Preah Vihear Formation magnetic susceptibilities falling in the middle [1].

The sandstone used in the Preah Vihear monument is mainly yellowish-brown (Fig. 3), and is medium to coarse grained. All the sandstone blocks of the Preah Vihear monument have magnetic susceptibility ranging from 0.011 to $0.068 \times 10^{-3}$ SI units, which is consistent with their supply from the Preah Vihear Formation. This accounts for the abundant ancient sandstone quarries widely distributed around the Preah Vihear monument, especially in the eastern and western areas, along the causeway between the Gopura IV(T) and Gopura V(W) (Fig. 3e, f).

Except for the Libraries ( $\mathrm{H} 1$ and $\mathrm{H} 2)$ had higher $\mathrm{Sr}$ contents of 58 and $56 \mathrm{ppm}$, respectively, the Sr contents in sandstone blocks from the other buildings were less than $30 \mathrm{ppm}$. According to Uchida et al. [1], the Sr content of the Preah Vihear Formation sandstone is typically less than $40 \mathrm{ppm}$. This also supports the premise that the sandstone blocks used in the Preah Vihear monument were quarried from the Preah Vihear Formation.

\section{Construction chronological sequence}

Using results described above, we delineated five construction stages for the Preah Vihear monument, as described below (Table 1; Fig. 2). In particular, the Ti and $\mathrm{Rb}$ contents, magnetic susceptibility, and size of the sandstone blocks, pediment end style, as well as the presence or absence of relief work on the tympana of the adjacent buildings were important factors for determining these stage divisions (Fig. 5).

We believe that the central part of the Western Annex Hall (N2) was constructed first (Fig. 6). The sandstone blocks in the upper structure of the central part of the Western Annex Hall (N2) are markedly smaller than those in the eastern and western parts of this Western Annex Hall (N2), as well as all other buildings in the monument. Their size is similar to sandstone blocks used in the sanctuaries of Phnom Krom and Phnom Bok of the Angkor area, constructed in the Bakheng style period (the end of the 9th century to the beginning of the 10th century). The sandstone blocks used in the platforms of Phnom Krom and Phnom Bok also are thin $(20-25 \times 35-45 \mathrm{~cm})$ compared with those used in their sanctuaries [20]. This block style also occurs in the platform of the Western Annex Hall (N2). In addition, the 


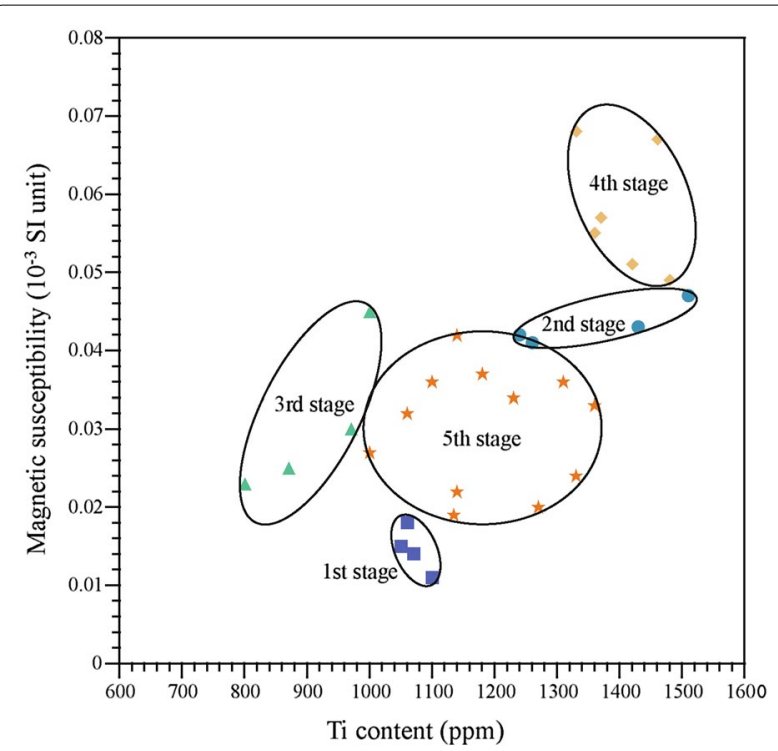

Fig. 5 Plot showing the average Ti contents vs average magnetic susceptibilities for sandstone blocks used in construction of the Preah Vihear monument. Data given in Table 1. Values are clearly characteristic of different stages of construction magnetic susceptibilities of the sandstone blocks in the upper structure of the central part of the Western Annex Hall (N2) are the lowest of any of the Preah Vihear monument. Furthermore, 54\% of the sandstone blocks of the upper structure of the central part of the Western Annex Hall (N2) have vertical bedding planes. This arrangement of blocks suggests that the central part of the Western Annex Hall (N2) was constructed in or before the Angkor Wat style period (before the end of the 12th century) [21]. Thus, the sandstone blocks and their arrangement in the upper structure of the central part of the Western Annex Hall (N2) are markedly different from those of the other parts of the Western Annex Hall (N2) and the other buildings. Their characteristics suggest that the upper structure of the central part of the Western Annex Hall (N2) was constructed in the Bakheng style period (the end of 9th century to the beginning of the 10th century). The platform of the central and western parts and the lower platform of the eastern part of the Western Annex Hall (N2) were likely constructed during the same period (Fig. 6), given that their sandstone blocks have similarly low magnetic susceptibilities.

Given that the tympana of the U-shaped Extensions (O1 and O2) adjacent to the Annex Halls (N1 and N2) are undecorated, but the other tympana are decorated, we concluded that the U-shaped Extensions (O1 and $\mathrm{O} 2)$ were constructed later than the Annex Halls (N1 and N2). Among these buildings, the Eastern Annex Hall (N1), Western U-shaped Extension (O2) and the eastern part (the upper structure and the upper platform) of the Western Annex Hall (N2) were constructed during the second stage. Pediments that end in scrolls made from one block are found in all these buildings. The sandstone blocks used in these buildings are relatively rich in $\mathrm{K}, \mathrm{Ti}, \mathrm{Fe}, \mathrm{Zn}, \mathrm{Rb}$, and $\mathrm{Zr}$. Although the Eastern U-shaped Extension (O1) has pediments that end in scrolls made from one block, its sandstone blocks have different chemical compositions and magnetic susceptibilities from those of the Eastern Annex Hall (N1), Western U-shaped Extension (O2), and the eastern part of the Western Annex Hall (N2). Therefore, the Eastern U-shaped Extension (O1) likely belongs to the third stage of construction. The sandstone blocks in the upper structure of the eastern part of the Western Annex Hall (N2) have similar chemical compositions to those in the Eastern Annex Hall (N1) and Western U-shaped Extension (O2). This suggests that the upper structure of the eastern part of the Western Annex Hall (N2) was extended while construction of the Eastern Annex Hall (N1) and Western U-shaped Extension (O2) was undertaken. The sandstone blocks in the upper structure of the western part of the Western Annex Hall (N2) have similar

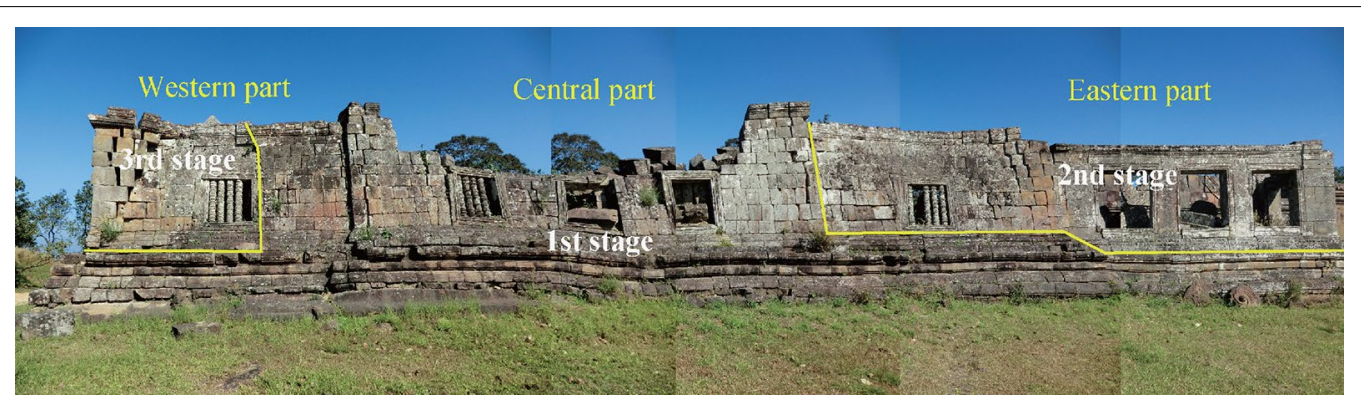

Fig. 6 Photograph of the southern face of the Western Annex Hall (N2) showing sections constructed during various stages. The central part (the platform and upper structure), the lower platform of the eastern part, and the platform of the western part were constructed first (first stage); the upper structure and upper platform of the eastern part followed (second stage); and finally, the upper structure of the western part was constructed (third stage) 
chemical compositions and magnetic susceptibilities to those of the Eastern U-shaped Extension (O1). This suggests that the upper structure of the western part of the Western Annex Hall (N2) was extended during the third stage, clearly later than the eastern part (second stage).

Given the similarity in style of the Eastern Annex Hall (N1) to the Khleang temple in the Angkor area, we believe that the second construction stage corresponds to the Khleang style period (the mid-10th century to the mid-11th century). The Eastern Annex Hall (N1) has an inscription (K381), which describes an event that took place in AD 1024 [10] or AD 1026 [12]. This suggests that the Eastern Annex Hall (N1) and Western U-shaped Extension $(\mathrm{O} 2)$ were completed around AD 1024 or $\mathrm{AD}$ 1026.

The Gopura V (W) was also likely constructed during the third stage, because its sandstone blocks have similar chemical compositions and magnetic susceptibilities to those of the Eastern U-shaped Extension (O1), and it has pediments that end in scrolls made from one block. The sandstone blocks used in the upper structure of the Western L-shaped Gallery (K2) are also similar in chemical compositions and magnetic susceptibilities to those of the Eastern U-shaped Extension (O1), suggesting that the upper structure of the Western L-shaped Gallery (K2) was constructed in this third stage. However, the Western L-shaped Gallery (K2) has pediments that end in scrolls made from two blocks, which are different from those in the Eastern U-shaped Extension (O1). Given the chemical compositions and magnetic susceptibilities of its constituent blocks, we consider the possibility that the platform of the Western L-shaped Gallery (K2) was constructed using the same sandstone blocks as those used in second-stage buildings. This is supported by the fact that the sandstone blocks of the third stage have distinctly lower $\mathrm{K}, \mathrm{Ti}, \mathrm{Fe}, \mathrm{Zn}, \mathrm{Rb}$, and $\mathrm{Zr}$ contents and magnetic susceptibilities than those of the second stage.

We infer that the Gopura III (P) was constructed after the U-shaped Extensions (O1 and O2) because reliefs were carved on the tympana of the U-shaped Extensions (O1 and $\mathrm{O} 2)$, but were left unfinished on those of the Gopura III (P) adjacent to the U-shaped Extensions (O1 and $\mathrm{O} 2)$. In addition to the Gopura III (P), Gopura II (L), Hall (J), Gopura I (G), Mandapa (C), and Eastern L-shaped Gallery (K1) were constructed in the fourth stage, characterized by sandstone blocks with relatively high $\mathrm{K}, \mathrm{Ti}, \mathrm{Fe}, \mathrm{Zn}, \mathrm{Rb}$, and $\mathrm{Zr}$ contents and magnetic susceptibilities. Medium-sized sandstone blocks were used in all of these buildings, except for the Gopura III (P). The Gopura III (P) has pediments that end in scrolls made from one block, while the Mandapa $(\mathrm{C})$ has pediments that end in five-headed nagas. The other buildings have pediments that end in scrolls made from two blocks.
Judging from the pediment end style, construction of the Gopura I (G), Hall (J), Gopura II (L), and Eastern L-shaped Gallery (K1), and then Mandapa (C) may have followed the construction of the Gopura III (P).

The sandstone blocks of the Gopura II (L) are similar in chemical compositions and magnetic susceptibilities to those of the Eastern L-shaped Gallery (K1), but differ from those of the Western L-shaped Gallery (K2). This suggests that the Eastern L-shaped Gallery (K1) was constructed at a different time to the Western L-shaped Gallery (K2) (during the second to third stages). The style of the pediment ends suggests that the Western L-shaped Gallery (K2) was constructed after the Gopura III (P). However, the construction sequence inferred from the style of the pediment ends contradicts that derived from the chemical compositions and magnetic susceptibilities of their sandstone blocks.

The inscription (K380) on the door frame of the Gopura II (L) consists of three sets of texts written in AD 1037-1038, AD 1038, and AD 1049, which describes events from AD 1018 [10-12]. This suggests that the Gopura II (L) was constructed at the end of the Khleang style period (the mid-11th century). Therefore, the buildings in the fourth stage are estimated to have been constructed from the end of the Khleang style to the Baphuon style (the mid-11th century to the end of 11th century) periods.

The remaining buildings at the site belong to the fifth stage. The sandstone blocks of these buildings have lower magnetic susceptibilities than those belonging to the second and fourth stages, and their chemical contents of $K$, $\mathrm{Ti}, \mathrm{Fe}, \mathrm{Zn}, \mathrm{Rb}$, and $\mathrm{Zr}$ fall between those of the second and fourth stages, and those of the third stage (Fig. 5).

The Western and Eastern Buildings ( $E$ and F) have pediments that end in scrolls made from two blocks; thus, we infer their construction slightly before the Central Sanctuary (B), Gallery (D), South Gopura (A), Gopura IV (T), and Libraries (H1 and $\mathrm{H} 2)$, which all have pediments that end in five-headed nagas. We believe that the Gopura IV (T) was constructed first among these buildings, because its sandstone blocks have square ends and almost half of them have vertical bedding planes, which are frequently seen in the platform.

In contrast to the other buildings, the sandstone blocks of the Libraries ( $\mathrm{H} 1$ and $\mathrm{H} 2$ ) are uniformly high in $\mathrm{Sr}$ and have similar magnetic susceptibilities to each other. This suggests that the Libraries ( $\mathrm{H} 1$ and $\mathrm{H} 2)$ were constructed at the same time. Given the site layout, we infer that the Libraries ( $\mathrm{H} 1$ and $\mathrm{H} 2)$ were constructed after the Gopura I (G), Hall (J), Gopura II (L), and Galleries (K1 and K2). This is supported by the fact that the Libraries (H1 and $\mathrm{H} 2$ ) have pediments that end in five-headed nagas, whereas the buildings surrounding the Libraries ( $\mathrm{H} 1$ and 
H2) have pediments that end in scrolls made from two blocks. Decoration also is more elaborate on the Libraries (H1 and H2), as well as on the Mandapa (C) and Hall (J), compared with other buildings in this stage.

The large sandstone blocks of the South Gopura (A), Central Sanctuary (B), Gallery (D), and Tower (Q) have similar chemical compositions and magnetic susceptibilities. In addition, these buildings, except for the Tower (Q), have pediments that end in five-headed nagas. Given these facts, we infer that these buildings were constructed at nearly the same time. Because the Tower $(\mathrm{Q})$ has no decoration and is unfinished, it may have been the last construction undertaken in the Preah Vihear monument. Because large sandstone blocks were used, with bedding planes that are mainly horizontal [21], the South Gopura (A), Central Sanctuary (B), and Gallery (D) are consistent with the Angkor Wat style period (the end of the 11th century to the end of the 12th century). In contrast, the Eastern Building (F), Western Building (E), Gopura IV (T), and Libraries ( $\mathrm{H} 1$ and $\mathrm{H} 1$ ) belong to the Baphuon style period (the mid-11th century to the end of the 11th century), and were constructed before the South Gopura (A), Central Sanctuary (B), and Gallery (D), based on their sandstone characteristics.

For comparison, the construction sequences for the Preah Vihear monument previously inferred by
Parmentier [9] and Sahai [12] are outlined in Table 2. Parmentier [9] used an architectural viewpoint, while Sahai [8] used inscriptions to establish a sequence. The sequence obtained in this study differs considerably from those obtained by both Parmentier [9] and Sahai [12]. Based on its sandstone block characteristics, we concluded that the Western Annex Hall (N2) is the oldest edifice in the Preah Vihear monument. This is not consistent with the construction sequences proposed by Parmentier [9] or Sahai [12]. They did not recognized that the Western Annex Hall (N2) was the oldest building in the construction sequence of the Preah Vihear monument. However, we support their inference that the Eastern Annex Hall (N1) and U-shaped Extensions (O1 and $\mathrm{O} 2)$ were constructed in the late Khleang style. Both authors considered that the Mandapa (C), Gopura I (G), Hall (J), and Gopura II (L) were constructed before the Annex Halls (N1 and N2) and U-shaped Extensions (O1 and O2). The South Gopura (A) and Gallery (D) also were inferred to be older than the Annex Halls (N1 and $\mathrm{N} 2)$ and U-shaped Extensions (O1 and O2) in their studies, being different from this study. Meanwhile, all studies support that the Gopura III (P) was constructed later than the Annex Halls (N1 and N2) and U-shaped Extensions (O1 and $\mathrm{O} 2)$. We concluded that the Gopura III (P), Gopura II (L), Hall (J), Gopura I (G), and Mandapa (C)

Table 2 Comparison of the constructions sequences for the Preah Vihear monument proposed by Parmantier [9], Sahai [12] and this study

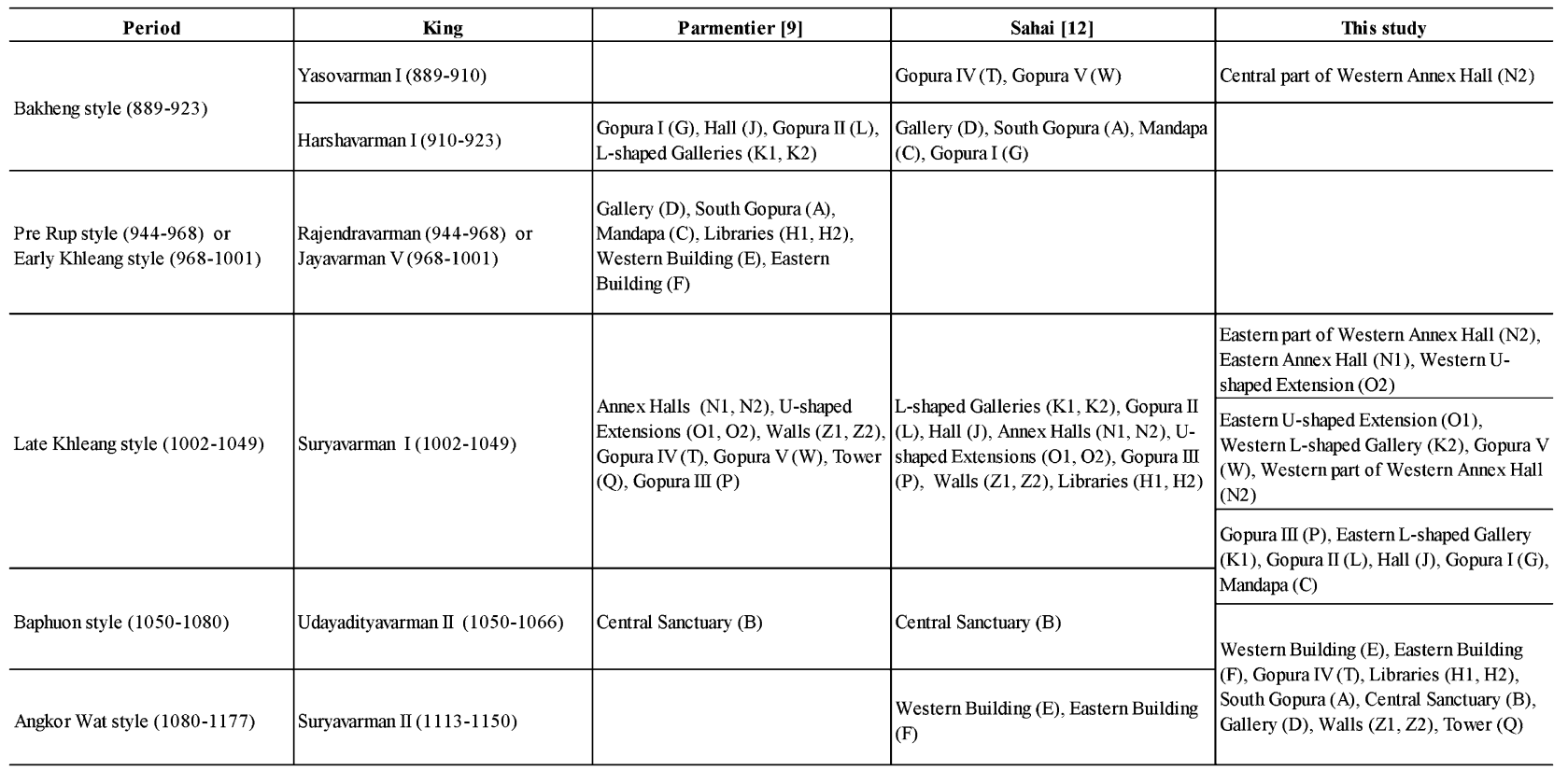


were constructed during the same period (in late Khleang style to the Baphuon style (the beginning of the 11th century to the end of the 11th century) based on their similar sandstone block chemical compositions and magnetic susceptibilities.

All three studies agree that the Central Sanctuary (B) was constructed in the final stage. However, Parmentier [9] and Sahai [12] considered the South Gopura (A) and Gallery (D) surrounding the Central Sanctuary (B) to have been constructed during the same period as the Mandapa (C). However, we found their sandstone block characteristics to be distinctly different. Large sandstone blocks were used in the South Gopura (A) and part of the Gallery (D) as well as in the Central Sanctuary (B), in contrast to the Mandapa $(C)$. In addition, the sandstone blocks of the South Gopura (A) and Gallery (D) are different in chemical compositions and magnetic susceptibilities from those of the Mandapa (C), but similar to those of the Central Sanctuary (B). Given these facts, it is difficult to accept the construction sequences for these buildings proposed by either Parmentier [9] or Sahai [12].

\section{Conclusions}

Using sandstone block chemical and magnetic characteristics, as well as stone arrangement and decoration, a construction sequence for the buildings in the Preah Vihear monument was established comprising five stages. The buildings and their distinctive stone characteristics are outlined below in order of their construction:

First stage (the Bakheng style period:the end of the 9th century to the beginning of the 10th century): initial construction of the upper structure of the central part and platform of the Western Annex Hall (N2) took place to form the oldest edifice in the Preah Vihear monument. The sandstone blocks in this stage are characterized by low magnetic susceptibilities, small block size, with a high percentage of vertical bedding planes. The stone block characteristics of the Western Annex Hall (N2) are completely different from the other buildings in the Preah Vihear monument. Previous works by Parmantier [9] and Sahai [12] did not recognized that this building was the oldest one in the construction sequence of the Preah Vihear monument.

Second stage (the middle Khleang style period:the early 11th century): ongoing construction of the upper structure of the eastern part of the Western Annex Hall (N2), Eastern Annex Hall (N1) (around AD 1024 or AD 1026), Western U-shaped Extension $(\mathrm{O} 2)$, and the platform of the Western L-shaped Gallery (K2) took place. The sandstone blocks used in this second stage are relatively enriched in $\mathrm{K}, \mathrm{Ti}, \mathrm{Fe}, \mathrm{Zn}, \mathrm{Rb}$, and $\mathrm{Zr}$ and have high magnetic susceptibilities.
Third stage (the late Khleang style period:the early 11th century to the mid-11th century): construction of the upper structure of the western part of the Western Annex Hall (N2), Eastern U-shaped Extension (O1), the upper structure of the Western L-shaped Gallery (K2), and Gopura V (W) took place. All buildings, except for the Western L-shaped Gallery (K2) constructed during the second and third stages, have pediments that end in scrolls made from one block. The sandstone blocks in the third stage are relatively depleted in $\mathrm{K}, \mathrm{Ti}, \mathrm{Fe}, \mathrm{Zn}, \mathrm{Rb}$, and $\mathrm{Zr}$. They also have low magnetic susceptibilities.

Fourth stage (the end of the Khleang style period to the Baphuon style period:the mid-11th century to the end of the 11th century): construction of the Gopura III (P), Eastern L-shaped Gallery (K1), Gopura II (L) (around AD 1038 or AD 1049), Hall (J), Gopura I (G), and Mandapa $(C)$ took place. The sandstone blocks used for these buildings are characterized by high magnetic susceptibilities and high $\mathrm{K}, \mathrm{Ti}, \mathrm{Fe}, \mathrm{Zn}, \mathrm{Rb}$, and $\mathrm{Zr}$ contents. The pediment terminations changed from scrolls to five-headed nagas.

Fifth stage (the Baphuon style period to the Angkor Wat style period:the mid-11th century to the end of the 12th century): construction of the Western Building (E), Eastern Building (F), Gopura IV (T), Libraries (H1 and H2), South Gopura (A), Central Sanctuary (B), Gallery (D), Walls (Z1 and Z2) near Libraries, and Tower $(\mathrm{Q})$ took place. Fifth-stage buildings are characterized by large sandstone blocks and pediments with five-headed nagas.

The construction sequence described above is almost in harmony with the change of pediment end styles from pediments ending in scrolls made from one block, to pediments ending in scrolls made from two blocks, and finally to pediments ending in five-headed nagas. In addition, the construction sequence suggests that the sandstone block size increased over time.

\section{Authors' contributions}

EU and AM conceived and coordinated this research. All authors conducted the field work. EU and AM interpreted data. EU drafted the manuscript and AM and IS revised it critically. All authors read and approved the final manuscript.

\section{Author details \\ ${ }^{1}$ Department of Resources and Environmental Engineering, Waseda Univer- sity, Ohkubo 3-4-1, Shinjuku-ku, Tokyo 169-8555, Japan. ${ }^{2}$ Department of Archi- tecture, Meijo University, Shiogamaguchi 1-501, Tenpaku, Nagoya 468-8502, Japan. ${ }^{3}$ World Heritage Studies, The University of Tsukuba, Kasuga 1-8-3, Tsukuba, Ibaraki 305-0821, Japan.}

\section{Acknowledgements}

This project was conducted with the co-operation of Ministry of Culture and Fine Arts and the National Authority for Preah Vihear, Cambodia. We would like to thank members of the Japanese Government Team for Safeguarding Angkor for their help during our research. We appreciate the useful and constructive comments received from three anonymous reviewers. 


\section{Competing interests}

The authors declare that they have no competing interests.

\section{Ethics approval and consent to participate}

Not applicable.

\section{Funding}

This research was supported financially in part by Grants-in-Aid for Scientific Research of the Japan Society for the Promotion of Science (Uchida: No. 23401001; and Mizoguchi: No. 24254005)

\section{Publisher's Note}

Springer Nature remains neutral with regard to jurisdictional claims in published maps and institutional affiliations.

Received: 19 April 2017 Accepted: 4 September 2017

Published online: 10 October 2017

\section{References}

1. Uchida E, Ito K, Shimizu N. Provenance of the sandstone used in the construction of the Khmer monuments in Thailand. Archaeometry. 2010:52:550-74. doi:10.1111/j.1475-4754.2009.00505.x.

2. Geological map of Cambodia, Laos, and Vietnam (at 1:1,000,000 scale). Geological Survey of Vietnam. 2nd eds. Hanoi: 1991.

3. Department of Mineral Resources of Thailand. Geological map of Thailand (at 1:1000,000 scale).1999.

4. Barth A. Inscriptions sanscrites du Cambodge. Paris: Imprimerie National; 1885.

5. Bergaigne A. Inscriptions sanscrites de Campa et du Cambodge. Paris: Imprimerie National; 1893

6. Aymonier E. Le Cambodge et ses monuments. Koh Ker, Phnom Sandak, Prah Vihear. In: Annales du Musée Guimet. Revue d'Histoire des Religions. Paris: Ernest Leroux; 1897. p. 20-54.

7. Lunet de Lajonquiere E. Inventaire descritif des monuments du Cambodge. Vol.II. Paris: Ernest Leroux; 1907.
8. Groslier G. Le temple de Preah Vihear, Art et Archéologies Khmères, I, Societé d'Éditions Géographiques, Maritimes et Colonials. 1921. Paris; 274-94.

9. Parmentier H. L'art Khmer Classique. Monuments du Quadrant Nord-Est. PEFEO: Paris; 1939. p. 362

10. Codès G. Inscriptions du Cambodge. EFEO. vol. 6, Hanoi: Paris; 1954.

11. Jacques C, Freeman M. Angkor: Cities and Temples. River Books. Bangkok; 1998. p. 319.

12. Sahai S. Preah Vihear. An introduction to the World Heritage Monument. Cambodian National Commission for UNESCO Phnom Penh; 2009. p. 213.

13. Roveda V. Preah Vihear. River Books Bangkok: 2000. p. 94.

14. Uchida E, Cunin O, Shimoda I, Suda C, Nakagawa T. The construction process of the Angkor monuments elucidated by the magnetic susceptibility of sandstone. Archaeometry. 2003;45:221-32. doi:10.1111/1475-4754.00105.

15. Uchida E, Cunin O, Suda C, Ueno A, Nakagawa T. Consideration on the construction process and the sandstone quarries during the Angkor period based on the magnetic susceptibility. J Archaeol Sci. 2007:34:92435. doi:10.1016/j.jas.2006.09.015.

16. Imai N, Terashima S, Itoh S, Ando A. 1994 compilation values for GSJ reference samples, "Igneous rock series". Geochem J. 1995;29:91-5.

17. Uchida E, Ogawa Y, Nakagawa T. The stone materials of the Angkor monuments, Cambodia-The magnetic susceptibility and the orientation of the bedding plane of the sandstone. J. Petrol. Mineral. Econ. Geol. 1998;93:411-26.

18. Uchida E, Shimoda I. Quarries and transportation routes of Angkor monument sandstone blocks. J Archaeol Sci. 2013;40:1158-64. doi:10.1016/j. jas.2012.09.036.

19. Meesook A. Cretaceous. In: Ridd MF, Barber AJ, Crow MJ, editors. The Geology of Thailand. Geological Society: London; 2011. p. 169-84.

20. Uchida E, Ando D. Petrological Survey 2000. In annual report on the technical survey of Angkor monument. Japanese Government Team for Safeguarding Angkor. 2001. p. 225-47.

21. Uchida E, Suda C, Ueno A, Shimoda I, Nakagawa T. Estimation of the construction period of Prasat Suor Prat in the Angkor monuments, Cambodia, based on the characteristics of its stone materials and the radioactive carbon age of charcoal fragments. J Archaeol Sci. 2005;32:1339-45. doi:10.1016/j.jas.2005.03.011.

\section{Submit your manuscript to a SpringerOpen ${ }^{\circ}$ journal and benefit from:}

- Convenient online submission

- Rigorous peer review

- Open access: articles freely available online

- High visibility within the field

- Retaining the copyright to your article

Submit your next manuscript at springeropen.com 